University of Nebraska - Lincoln

DigitalCommons@University of Nebraska - Lincoln

USDA National Wildlife Research Center - Staff Publications
U.S. Department of Agriculture: Animal and Plant Health Inspection Service

2019

\title{
Taking the bait: Species taking oral rabies vaccine baits intended for raccoons
}

\author{
Betsy S. Haley \\ USDA/APHIS/WS-NRMP, Concord, NH, betsy.s.haley@aphis.usda.gov
}

Are R. Berentsen

USDA/APHIS/WS/National Wildlife Research Center, Are.R.Berentsen@aphis.usda.gov

Richard M. Engeman

APHIS, s_r100@yahoo.com

Follow this and additional works at: https://digitalcommons.unl.edu/icwdm_usdanwrc

Part of the Natural Resources and Conservation Commons, Natural Resources Management and Policy Commons, Other Environmental Sciences Commons, Other Veterinary Medicine Commons, Population Biology Commons, Terrestrial and Aquatic Ecology Commons, Veterinary Infectious Diseases Commons, Veterinary Microbiology and Immunobiology Commons, Veterinary Preventive Medicine, Epidemiology, and Public Health Commons, and the Zoology Commons

Haley, Betsy S.; Berentsen, Are R.; and Engeman, Richard M., "Taking the bait: Species taking oral rabies vaccine baits intended for raccoons" (2019). USDA National Wildlife Research Center - Staff Publications. 2251.

https://digitalcommons.unl.edu/icwdm_usdanwrc/2251

This Article is brought to you for free and open access by the U.S. Department of Agriculture: Animal and Plant Health Inspection Service at DigitalCommons@University of Nebraska - Lincoln. It has been accepted for inclusion in USDA National Wildlife Research Center - Staff Publications by an authorized administrator of DigitalCommons@University of Nebraska - Lincoln. 


\title{
Taking the bait: species taking oral rabies vaccine baits intended for raccoons
}

\author{
Betsy S. Haley ${ }^{1} \cdot$ Are R. Berentsen $^{2} \cdot$ Richard M. Engeman $^{2}$ \\ Received: 9 August 2018 / Accepted: 8 January 2019 / Published online: 8 February 2019 \\ (C) This is a U.S. government work and not under copyright protection in the U.S.; foreign copyright protection may apply 2019
}

\begin{abstract}
Raccoon rabies in eastern USA is managed by strategically distributing oral rabies vaccine (ORV) baits. The attractiveness, palativity, density, and non-target species bait take affect ORV effectiveness. We examined raccoon and non-target species differences in investigating/removing fish-meal polymer and coated sachet baits applied to simulate two aerial bait distribution densities. Bait densities of $150 \mathrm{baits} / \mathrm{km}^{2}$ and $75 \mathrm{baits} / \mathrm{km}^{2}$ were evaluated, respectively, in zones expected to have high and low raccoon densities. Three primary non-target species visited baits: coyotes, white-tailed deer, and feral swine. The proportion of bait stations visited by raccoons during 1 week observation periods ranged from 50 to $70 \%$, exceeding non-target species visitation. Raccoon take rates for visited baits averaged from 59 to $100 \%$. Raccoon visitation was similar for both bait densities, indicating a proportionally greater quantity of baits were taken in the higher bait density zone. Coyote visitation rates ranged from 16 to $26 \%$, with take rates for visited baits between 46 and 100\%. Coyotes were expected to take baits intended for raccoons, because similar baits are applied to vaccinate coyotes. Deer regularly investigated but rarely took baits. Feral swine were in low abundance in the high bait density zone (higher human density) and visited $\leq 1 \%$ of baits there but visited baits at frequencies similar to coyotes and deer in the low-density zone and were likely to take encountered baits (63-100\%). Non-target bait consumption could be a concern in some circumstances for achieving sufficient raccoon sero-conversion rates.
\end{abstract}

Keywords Bait density $\cdot$ Coated sachet $\cdot$ Epizootic $\cdot$ Fish-meal polymer $\cdot$ Non-target species $\cdot$ ORV

\section{Introduction}

In the USA, the first rabid raccoon (Procyon lotor) was reported in 1936 (CA Dept. of Public Health 1938), with only sporadic cases reported from 1936 to 1950 (Jenkins and Winkler 1987). In the 1950s, an outbreak occurred in central Florida, which marked the beginning of an epizootic (Scatterday et al. 1960). In 1977-1978, four raccoon-variant rabies-positive raccoons were found in Virginia and West Virginia, sparking a second epizootic that quickly spread through Maryland,

Responsible editor: Philippe Garrigues

Richard M. Engeman

Richard.m.engeman@aphis.usda.gov

1 USDA/APHIS/WS-NRMP, 59 Chennell Dr, Suite 2, Concord, NH 03301, USA

2 USDA/APHIS/WS National Wildlife Research Center, 4101 LaPorte Ave, Fort Collins, CO 80521-2154, USA
Pennsylvania, and the District of Columbia (Jenkins and Winkler 1987). By 1983, over 1500 rabid raccoons had been reported along the Eastern US seaboard and raccoon-variant rabies since spread north into Canada and west to Ohio, eastern Tennessee, and southwestern Alabama (Blanton et al. 2010; Slate et al. 2008; Wandeler and Salsberg 1999; Jenkins and Winkler 1987).

In response to these outbreaks, the US Department of Agriculture (USDA), in cooperation with state agencies and others, began implementing an oral rabies vaccination program during the 1990s (Slate et al. 2008). Currently, the USDA/National Rabies Management Program (NRMP) manages rabies in terrestrial wildlife in the USA through the distribution of oral rabies vaccine (ORV) (Slate et al. 2005). Oral rabies vaccines are distributed throughout the eastern and portions of the southwestern USA. Target species include raccoons, gray foxes (Urocyon cinereoargenteus), and coyotes (Canis latrans). In 1994, an outbreak of rabies in coyotes and domestic dogs in Texas led to a statewide emergency and aggressive pet vaccination programs, including ORV distribution targeting coyotes and gray fox (e.g., Sidwa et al. 
2005). Collectively, these programs led to the USA being declared free of canine rabies in 2007 (Slate et al. 2009).

Previous research into oral rabies vaccine bait acceptance has focused primarily on flavor preference (Linhart et al. 1991, 2002; Rosatte et al. 1998) or bait structure (Jojola et al. 2007; Steelman et al. 1998, 2000). Other research has examined raccoon bait take relative to density, baiting strategy, delivery mechanisms, with some assessment of non-target competition for ORV baits (e.g., Blackwell et al. 2004; Boulanger et al. 2008; Johnson et al. 2016; Smyser et al. 2010, 2015). Such research is vital in designing effective vaccine delivery mechanisms and strategies. Baits can become unpalatable with increasing environmental exposure (Berentsen et al. 2014), and competition from non-target species such as opossums (Didelphis virginianus) or domestic cats (Felis silvestris catus) may affect bait availability (Olson et al. 2000; Roscoe et al. 1998). Olson et al. (2000) evaluated non-target uptake of ORV baits, but in that study, baits were distributed randomly and did not provide an accurate representation of aerial bait distribution as practiced operationally.

The utility of a bait type for delivering an oral vaccine to the target species is reliant on the bait being sufficiently attractive such that target animals will investigate, and ultimately be palatable, leading to bait consumption. It is also important that the target animal has sufficient opportunity to find baits. Thus, baits should be distributed in sufficient density that all target animals in the baited area have an opportunity to encounter baits and that sympatric species do not compete with target animals, preventing their opportunity to consume at least one bait.

Our objectives were to evaluate the fate of two types of ORV baits when distributed by aircraft. Specifically, we were interested in knowing (1) the number and types of non-target species investigating or removing baits, (2) bait type preference (fish-meal polymer vs. coated sachet), and (3) if differences existed among objectives 1 and 2 with respect to application bait density.

\section{Methods}

\section{Study design}

Our study was conducted in Pasco County, Florida. We established two study zones: one each on the west and east sides of US Interstate 75 (I-75), a major north-south highway in western Florida (Fig. 1). The land areas on either side of I-75 were characterized by mixed habitats comprised of pasturelands/grasslands and mixed deciduous and evergreen forest. The area west of I-75 (coastal side) had a much larger human population density than on the east side. Raccoon populations can thrive and reach extreme densities in such areas (Prange et al. 2003, Smith and Engeman 2002, Rosatte et al.
1991, Riley et al. 1998), implying the potential need for a greater bait density (USDA 2005; Slate et al. 2015). To account for presumed higher raccoon population density at the time, aerial baiting programs applied to the west side of I-75 were operationally baited with ORV baits at a density (150 baits $/ \mathrm{km}^{2}$ ), twice the ORV bait density applied to the east side (75 baits $/ \mathrm{km}^{2}$ ) (USDA 2005).

In 2005, we established 6 plots within each zone, each with 24 bait stations. The same plots and bait stations were also used in 2006, with the exception of the eastern zone when only five of the original six plots could be used. Four transects were established in each plot with 500-m separating transects. For plots in the eastern (lower raccoon density) zone, bait stations were placed at $26.6 \mathrm{~m}$ intervals along each transect $\left(75\right.$ baits $\left./ \mathrm{km}^{2}\right)$, while the plots in the western zone had baits placed at $13.3 \mathrm{~m}$ intervals (150 baits $/ \mathrm{km}^{2}$ ) to simulate operational ORV baiting densities on both sides of I-75.

Each bait station was made by clearing $1 \mathrm{~m}^{2}$ of vegetation and placing a single ORV bait in the middle of each sandy station. In 2005, three of the six plots in each zone were baited with fish-meal polymer (FMP) baits and the other three were baited with coated sachet (CS) baits (72 baits of each type per zone in total). In 2006, the bait types in each plot were reversed from 2005. However, in the east zone, 2 plots instead of 3 were baited with FMP baits (48 stations total), because one of the plots had to be removed from the study due to a vegetation project by the landowner, and 3 plots still were baited with CS baits (72 stations). After bait placement, the stations in each plot were monitored daily for 1 week. We recorded whether the bait had been removed (presence/absence) and, by recording tracks, the species visiting the bait, and the likely or potential species responsible for bait removal.

\section{Analyses}

We evaluated the proportion of baits investigated by raccoons in each plot during each observation period. We also evaluated the probability that investigated baits were subsequently consumed, by calculating the proportion of baits at stations with raccoon tracks that also had the bait missing. When a missing bait had also been visited by another species besides raccoon, we considered both scenarios for bait take: a raccoon was responsible or another species was responsible. This presented two possibilities for assessing the probability that baits encountered by a raccoon were removed by raccoons. The first was to define a minimum bound for raccoon bait take by calculating the proportion of times baits were removed from stations where only raccoon tracks were observed at the station. Clearly, if raccoon tracks and tracks from other species were present, those baits also could have been removed by raccoons. Thus, a maximal bound on the proportion of times baits were removed from stations with raccoon tracks would be to consider all baits to have been removed by raccoons, 


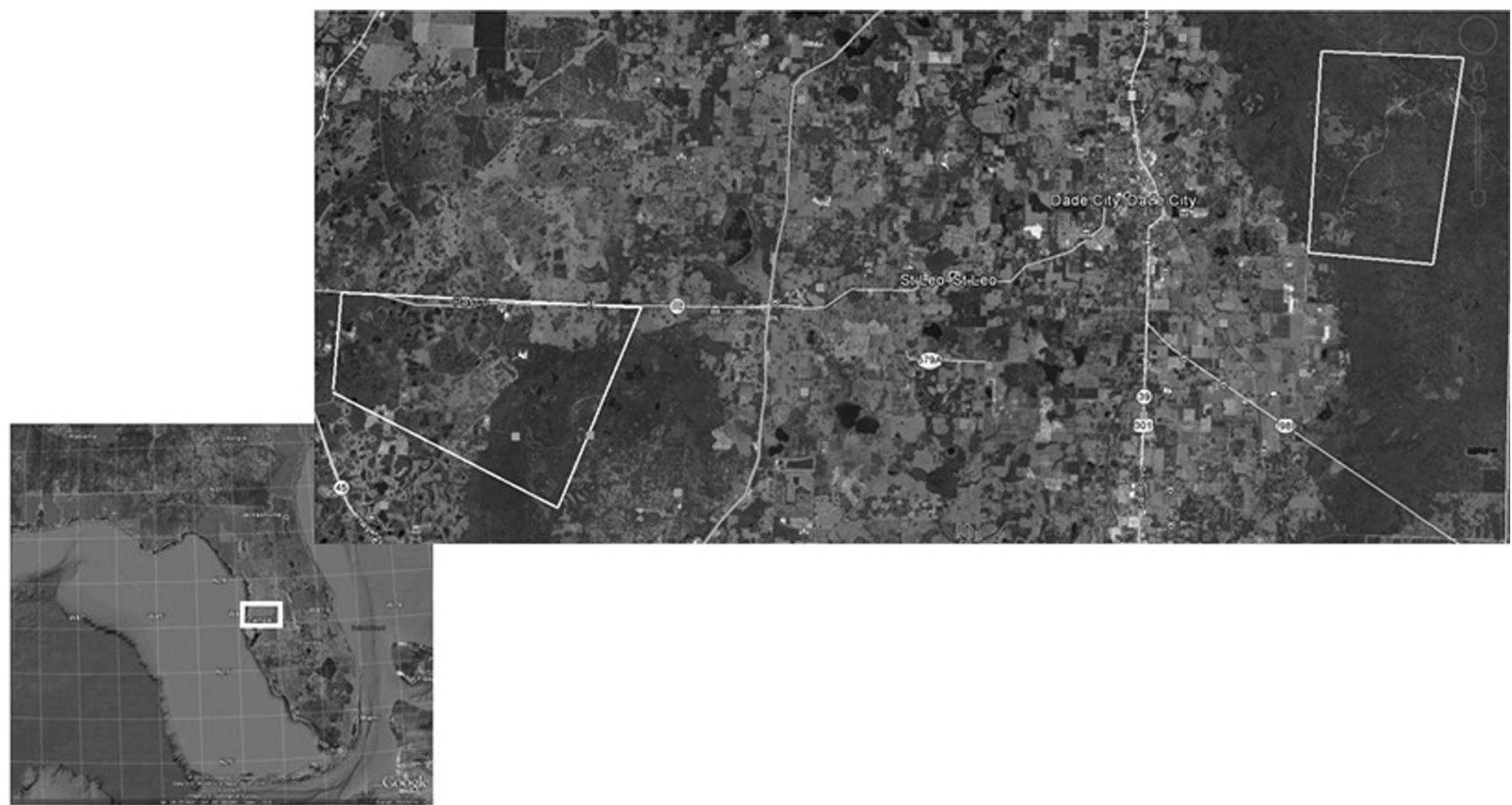

Fig. 1 Location of study zones in Pasco County, Florida, for examining species taking two types of rabies baits intended for raccoons. To account for differential raccoon densities, the western zone was baited with oral

even when other species tracks were present. Clearly, the true proportion of baits encountered by raccoons that were taken by raccoons would be between these bounds. We applied this same approach for the other prominent species observed to take baits. Thus, for each plot for each observation occasion, we calculated a minimum and a maximum probability that a particular species would take a bait it encountered. Because the true probability would lie between the minimal and maximum probabilities, we considered designation of a "most likely" category to be unnecessary and would insert too much subjectivity into the metric. The proportion of baits visited with only tracks from one species present provides a gauge of how attractive that bait was to that animal species.

The proportions of all baits distributed that were investigated by each species and the minimum and maximum proportions of baits encountered that were taken by each species were assessed descriptively and also analyzed as a two-factor repeated-measures ANOVA, where plots were nested in bait density and bait type was the repeated factor on each plot.

\section{Results}

Besides raccoons, a variety of non-target species visited the baits at least once (Table 1). Importantly, three of the nontarget species, coyotes, feral swine (Sus scrofa), and whitetailed deer (Odocoileus virginianus), consistently visited bait stations, including where baits were removed. Table 2 shows rabies vaccine (ORV) baits at a density 150 baits $/ \mathrm{km}^{2}$, while the eastern zone was baited at 75 baits $/ \mathrm{km}^{2}$

the mean proportions of offered baits that were investigated by raccoons, coyotes, swine, and deer. Mean visitation rates by raccoons $(50-70 \%)$ exceeded those for the non-target species (0-36\% across all non-target species). Thirty-six percent of FMP baits in the high bait density plots were visited by deer, and $26 \%$ of FMP baits in the high bait density plots were visited by coyotes. Raccoon mean visitation rates appeared higher for FMP baits in both the low and high bait density areas (Table 2), but due to the variable nature of visitation rates, statistical differences were not detected between bait types ( $\left.\mathrm{F}_{1,9}=1.88, p=0.20\right)$ or the bait type-by-bait density interaction $\left(\mathrm{F}_{1,9}=0.32, p=0.59\right)$.

Visitation rates by deer were greater at the high bait density, due to the high visitation rate to FMP baits in the high bait density area (Table 2, $\mathrm{F}_{1,10}=7.55, p=0.021$ ). Feral swine had higher visitation rates to both FMP and CS baits in the low bait density area (Table 2, $\mathrm{F}_{1,9}=21.23, p=0.001$ ), than in the high bait density plots. Coyote visitation rates were essentially the same across bait types and bait densities except for the abovementioned FMP baits in the high-density zone, where visitation was $63 \%$ higher than for the other three bait type-bait density combinations.

In both the low and high bait density areas, no pattern was evident among take rates for the two bait types when considering only bait stations having only raccoon tracks (low proportion values for both baits) (Table 3 ). When considering all potential take of offered baits by raccoons including when the tracks other species were present, the FMP take rate appeared 
Table 1 Wildlife species in Pasco County Florida recorded through tracks as having visited oral rabies vaccine (ORV) baits placed in tracking stations. The overall visitation rates for all species across all observation days and all bait stations (station-days) are listed in order in the third column. The only vertebrate tracks consistently observed at the tracking plots with ORV baits were from raccoons, coyotes, white-tailed deer, and feral swine

\begin{tabular}{lll}
\hline Species common name & Scientific name & Overall \% of station-days with tracks \\
\hline Raccoon & Procyon lotor & 21.2 \\
White-tailed deer & Odocoileus virginianus & 16.4 \\
Coyotes & Canis latrans & 9.3 \\
Feral swine & Sus scrofa & 8.9 \\
Fire ants & Solenopsis spp. & 6.1 \\
Gray fox & Urocyon cinereoargenteus & 2.9 \\
Eastern cottontail rabbit & Sylvilagus floridanus & 2.6 \\
Turkey & Meleagris gallopavo & 2.1 \\
Nine-banded armadillo & Dasypus novemcinctus & 1.7 \\
Virginia opossum & Didelphis virginiana & 0.8 \\
Eastern gray squirrel & Sciurus carolinensis & 0.5 \\
\hline
\end{tabular}

higher than for CS baits at both bait densities, but differences were not statistically detectable $\left(\mathrm{F}_{1,9}, \mathrm{~F}_{1,10}<2.16, p>0.18\right.$, across all tests) between bait types, bait densities, or their interaction (Table 2). In the high bait density area, feral swine rarely visited baits and therefore only took small proportions of offered baits (Tables 2 and 3). Even in the low bait density area where feral swine visitation rates were higher, the mean take rates of all offered baits by feral swine were relatively low (8-16\%). When considering deer take only at stations having only deer tracks, the take rate was low (e.g., zero times in the low bait density and $2-4 \%$ in the high bait density) (Table 3 ). The potential maximal take rates of all offered baits when deer tracks occurred with tracks from other species-maximum proportion - were 12-36\% across all bait type and bait density combinations (Table 3 ). Take rates of all offered baits by coyotes were $21-49 \%$ of observed take rates for raccoons, and considerably higher than for the other non-target species, considering both the minimum and maximum take rate proportions (Table 3 ).

When examining bait stations with tracks from a single species, it was clear that there was a high likelihood if the species present was a raccoon, coyote, or feral swine, it would take the bait (46-100\%) (Table 4). If only deer tracks were present, the likelihood the bait would be taken was 4-21\% (Table 4). Given a visit to a bait station only by a raccoon (only raccoon tracks present), the minimal take rates (Table 4) were between 59 and 79\%, a high probability of bait take given a raccoon visit, and maximal take rates including when tracks of other species were present were between 96 and 100\% (Table 4). Differences again were not detected statistically between bait types, bait densities, or their interaction for either the minimum or maximum raccoon take rate variables (Table $3, \mathrm{~F}_{1,9}, \mathrm{~F}_{1,10}<$ $1.59, p>0.24$, across all tests). While bait visitation rates for feral swine were only $0-16 \%$ (Table 2 ), the minimal take rates by swine when only their tracks were present was $63-100 \%$ (Table 4). Deer presented a more complicated result. When only deer tracks were found at a bait station, the bait was rarely missing (0-4\%), except for CS baits in the high bait density zone where $21 \%$ of visited baits were taken (Table 4). However, when deer were considered the species taking the bait when their tracks occurred with those of other species (maximum proportion, Table 4), take rates were much larger (80-100\%). Given the low proportion (deer track only) results, it appeared that deer did not regularly or consistently take the baits when they visited bait stations. Take rates by coyotes, given that they were the only species that visited a bait station, were 46-100\%, minimum rate (Table 4), while the maximal take rates were high (95-100\%) when considering that a coyote took the baits when tracks from other species were also present (Table 4).
Table 2 The mean proportion of distributed oral vaccine bait types that were visited by raccoons and prominent sympatric species in Pasco County, Florida. Two bait types were considered: fish-meal polymer (FMP) and coated sachet (CS). Baits were placed in stations at two simulated bait densities: 75 baits $/ \mathrm{km}^{2}$ (low) and 150 baits/ $\mathrm{km}^{2}$ (high)

\begin{tabular}{lllllll}
\hline Bait density & Bait type & Number & \multicolumn{2}{l}{ Mean visitation rates } \\
\cline { 3 - 6 } & & & Raccoon & Coyote & White-tailed deer & Feral swine \\
\hline \multirow{2}{*}{ High } & CS & 6 & 0.53 & 0.17 & 0.17 & 0.00 \\
& FMP & 6 & 0.60 & 0.26 & 0.36 & 0.01 \\
\multirow{2}{*}{ Low } & CS & 6 & 0.50 & 0.16 & 0.12 & 0.16 \\
& FMP & 5 & 0.70 & 0.16 & 0.16 & 0.13 \\
\hline
\end{tabular}


Table 3 The mean take rates for raccoons and prominent sympatric species in Pasco County, Florida for all offered oral vaccine bait types (without regard to whether bait stations were visited or not). Two take rates were calculated for each species. The minimum take rate is when only that species had visited the bait station. The maximum rate is when the species was assumed to have been the one to take the bait when multiple species had visited the bait station. Two bait types were considered: fish-meal polymer (FMP) and coated sachet (CS). Baits were placed in stations at two simulated bait densities: 75 baits $/ \mathrm{km}^{2} 150$ baits $/ \mathrm{km}^{2}$

\begin{tabular}{|c|c|c|c|c|c|c|c|c|c|c|}
\hline \multirow[t]{3}{*}{ Bait density } & \multirow[t]{3}{*}{ Bait type } & \multirow[t]{3}{*}{ Number } & \multicolumn{8}{|c|}{ Mean take rates of all available baits } \\
\hline & & & \multicolumn{2}{|l|}{ Raccoon } & \multicolumn{2}{|l|}{ Coyote } & \multicolumn{2}{|c|}{ White-tailed deer } & \multicolumn{2}{|l|}{ Feral swine } \\
\hline & & & Minimum & Maximum & Minimum & Maximum & Minimum & Maximum & Minimum & Maximum \\
\hline \multirow[t]{2}{*}{ High } & $\mathrm{CS}$ & 6 & 0.40 & 0.51 & 0.14 & 0.16 & 0.04 & 0.17 & 0.00 & 0.00 \\
\hline & FMP & 6 & 0.35 & 0.59 & 0.17 & 0.26 & 0.02 & 0.36 & 0.01 & 0.01 \\
\hline \multirow[t]{2}{*}{ Low } & $\mathrm{CS}$ & 6 & 0.34 & 0.49 & 0.10 & 0.15 & 0.00 & 0.12 & 0.10 & 0.16 \\
\hline & FMP & 5 & 0.43 & 0.70 & 0.09 & 0.16 & 0.00 & 0.16 & 0.08 & 0.13 \\
\hline
\end{tabular}

\section{Discussion}

The strategy of increasing bait density to account for presumed greater raccoon populations appeared advantageous. The proportions of baits visited and taken by raccoons were similar between the low and high bait density zones, indicating a proportionally greater quantity of baits were taken in the zone with a presumed greater raccoon population.

While raccoon visitation and take rates for FMP baits were consistent, albeit marginally higher (not statistically distinguishable), than for CS baits, the lower cost of CS becomes a deciding factor, allowing far greater area to be baited, sometimes at 150 baits $/ \mathrm{km}^{2}$. Other studies in Georgia, Ohio, and Texas found similar results with no statistical differences between CS and FMP bait visitation or removal rates by raccoons or coyotes (Linhart et al. 2002).

A rudimentary knowledge of the abundance of non-target species that might also take baits intended for raccoons could influence decisions on bait densities. For example, feral swine are considered among the more notorious invasive species in the state and are ubiquitous over most regions of Florida (e.g.,
Engeman et al. 2009; Hardin 2007; Rodgers et al. 2014; Seward et al. 2004). Their omnivorous diets are highly diverse, and they will readily condition to food sources (e.g., Engeman et al. 2016; Seward et al. 2004). Nevertheless, while capable of existing and causing damage in urbanized areas (Seward et al. 2004), they are less likely to be found in densities they achieve in rural areas. This was borne out in our data where bait visitation was $\leq 0.01$ in the high bait density (urbanized) zone (Table 2), whereas feral swine could have accounted for up to $16 \%$ of bait visitations in the low bait density zone (Tables 2). Nevertheless, when only feral swine visited a bait, they were very likely to take the bait, $63-100 \%$ (Table 4).

Deer consistently visited baits, and many of those baits were removed. However, when only deer visited baits, a low percent of the visited baits were removed (0-21\%). Thus, deer appeared to pose only a minimal threat as non-target bait competitors and probably do not substantially impact the availability of baits to raccoons.

Coyotes are considered an invasive species by the State of Florida (Schmitz and Brown 1994) and have been increasing
Table 4 The mean take rates by raccoons and prominent sympatric species in Pasco County, Florida of distributed oral vaccine bait types only for stations visited by each species. Two take rates were calculated for each species. The minimum take rate is when only that species had visited the bait station. The maximum rate is when the species was assumed to have been the one to take the bait when multiple species had visited the bait station. Two bait types were considered: fish-meal polymer (FMP) and coated sachet (CS). Baits were placed in stations at two simulated bait densities: 75 baits $/ \mathrm{km}^{2}$ (low) and $150 \mathrm{baits} / \mathrm{km}^{2}$ (high). Take rates could not be calculated for feral swine take to CS bait stations in the high bait density zone, because there were no feral swine visits

\begin{tabular}{|c|c|c|c|c|c|c|c|c|c|c|}
\hline \multirow[t]{3}{*}{ Bait density } & \multirow[t]{3}{*}{ Bait type } & \multirow[t]{3}{*}{ Number } & \multicolumn{8}{|c|}{ Mean take rates given a visit to a bait station } \\
\hline & & & \multicolumn{2}{|l|}{ Raccoon } & \multicolumn{2}{|l|}{ Coyote } & \multicolumn{2}{|c|}{ White-tailed deer } & \multicolumn{2}{|l|}{ Feral swine } \\
\hline & & & Minimum & Maximum & Minimum & Maximum & Minimum & Maximum & Minimum & Maximum \\
\hline \multirow[t]{2}{*}{ High } & $\mathrm{CS}$ & 6 & 0.79 & 0.96 & 0.82 & 0.95 & 0.21 & 0.80 & na & na \\
\hline & FMP & 6 & 0.59 & 0.99 & 0.46 & 1.00 & 0.04 & 1.00 & 1.00 & 0.60 \\
\hline \multirow[t]{2}{*}{ Low } & CS & 6 & 0.66 & 0.97 & 0.57 & 0.98 & 0.00 & 1.00 & 0.69 & 1.00 \\
\hline & FMP & 5 & 0.61 & 1.00 & 1.00 & 1.00 & 0.00 & 1.00 & 0.63 & 1.00 \\
\hline
\end{tabular}


in number and expanding their range in Florida (Coates et al. 2002; Wooding and Hardisky 1990). In Texas, similar ORV baits are distributed to manage rabies in coyotes (e.g., Sidwa et al. 2005; Slate et al. 2005). Thus, coyotes are a non-target species that would be expected to take a portion of baits intended for raccoons, especially where coyotes are abundant. Like raccoons, coyotes can readily adapt to and benefit from urbanized areas (e.g., Gehrt et al. 2011). This, too, was borne out in our results where bait visitation rates were similar in low- and high-density areas, except for much higher rates for the FMP baits in the high bait density zone. With bait visitation rates between 16 and $26 \%$ and subsequent take rates between 46 and 100\% (Table 4), coyotes have the potential to reduce opportunities for baits to be taken by raccoons. Coyotes can be an important rabies host, so even though raccoon vaccination rates may suffer in areas of high coyote density, there is potential benefit from coyotes consuming ORV baits.

Up to a $70 \%$ vaccination rate may be required to prevent rabies spread in some species (Thulke and Eisinger 2008; WHO 1987), possibly making non-target consumption of ORV baits a concern in some circumstances for achieving high enough seroprevalence to eliminate raccoon-variant rabies.

Acknowledgments We thank Bernice Constantin for his support of this project.

Publisher's note Springer Nature remains neutral with regard to jurisdictional claims in published maps and institutional affiliations.

\section{References}

Berentsen AR, Pitt WC, Eisemann JD, Engeman RM (2014) Longevity of rodenticide bait pellets in a tropical environment following a rat eradication program. Environ Sci Pollut Res 21:2283-2288

Blackwell BF, Seamans TW, White RJ, Patton ZJ, Bush RM, Cepek JD (2004) Exposure time of oral rabies vaccine baits relative to baiting density and raccoon population density. J Wildl Dis 40:222-229

Blanton JD, Palmer D, Dyer J, Rupprecht CE (2010) Rabies surveillance in the United States during 2010. J Am Vet Med Assoc 239:773-783

Boulanger JR, Bigler LL, Curtis PD, Lein DH, Lembo AJ Jr (2008) Comparison of suburban vaccine distribution strategies to control raccoon rabies. J Wildl Dis 44:1014-1023

Coates SF, Main MB, Mullahey JJ, Schaefer JM, Tanner GW, Sunquist ME, Fanning MD (2002) The coyote (Canis latrans): Florida's newest predator. WEC124, Florida cooperative extension service, Institute of Food and Agricultural Sciences, University of Florida, Gainesville

Engeman RM, Constantin BU, Hardin S, Smith HT, Meshaka WE Jr (2009) "Species pollution" in Florida: a cross-section of invasive vertebrate issues and management responses. In: Wilcox CP, Turpin RB (eds) Invasive species: detection, impact and control. Nova Science Publishers, Hauppauge, pp 179-197

Engeman RM, Addison D, Griffin JC (2016) Defending against disparate sea turtle nest predators: benefits to nesting success from eradicating invasive feral swine and caging nests from raccoons. Oryx 50(2): 289-295
Gehrt SD, Brown JL, Anchor C (2011) Is the urban coyote a misanthropic Synanthrope? The case from Chicago. Cities Environ 4(1):3 Available at: http://digitalcommons.lmu.edu/cate/vol4/iss1/3

Hardin S (2007) Managing non-native wildlife in Florida: state perspective, policy and practice. In: Witmer G, Pitt W, Fagerstone K (eds.) Managing Vertebrate Invasive Species: Proceedings of an International Symposium. Fort Collins, CO: USDA/APHIS/WS National Wildlife Research Center. pp. 43-52

Jenkins SR, Winkler WG (1987) Descriptive epidemiology from an epizootic of raccoon rabies in the middle Atlantic states, 1982-1983. Am J Epidemiol 126:429-437

Johnson SR, Crider NJ, Weyer GA, Tosh RD, VerCauteren KC (2016) Bait development for oral delivery of pharmaceuticals to raccoons (Procyon lotor) and striped skunks (Mephitis mephitis). J Wildl Dis 52:893-901. https://doi.org/10.7589/2015-12-322

Jojola SM, Robinson SJ, VerCauteren KC (2007) Oral rabies vaccine (ORV) bait uptake by captive striped skunks. J Wildl Dis 43:97-106

Linhart SB, Blom FS, Dasch GJ, Roberts JD, Engeman RM, Esposito JJ, Shaddock JH, Baer GM (1991) Formulation and evaluation of baits for oral rabies vaccination of raccoons (Procyon lotor). J Wildl Dis 27:21-33

Linhart SB, Wlodkowski JC, Kavanaugh DM, Motes-Kreimeyer L, Montoney AJ, Chipman RB, Slate D, Bigler LL, Fearneyhouth MG (2002) A new flavor-coated sachet bait for delivering oral rabies vaccine to raccoons and coyotes. J Wildl Dis 35:363-377

Olson CA, Mitchell KD, Werner PA (2000) Bait ingestion by freeranging raccoons and nontarget species in an oral rabies vaccine trial in Florida. J Wildl Dis 36:734-743

Prange S, Gehrt SD, Wiggers EP (2003) Demographic factors contributing to high raccoon densities in urban landscapes. J Wildl Manag 67: 324-333

Riley SPD, Hadidian J, Manski DA (1998) Population density, survival, and rabies in raccoons in an urban national park. Can J Zool 76: $1153-1164$

Rodgers L, Black D, Bodle M, Laroche F (2014) The status of nonindigenous species in the South Florida environment. In: 2014 South Florida Environmental Report, vol I. South Florida Water Management District, West Palm Beach, Chapter 7, pp 7-1-7-53

Rosatte RC, Power MJ, MacInnes CD (1991) Ecology of urban skunks, raccoons, and foxes in metropolitan Toronto. In: Adams LW, Leedy DL (eds) Wildlife conservation in metropolitan environments. National Institute for Urban Wildlife, Columbia, pp 31-38

Rosatte RC, Lawson KF, MacInnes CD (1998) Development of baits to deliver oral rabies vaccine to raccoons in Ontario. J Wildl Dis 34: $647-652$

Roscoe DW, Holste WC, Sorhate FE, Campbell C, Niezgoda M, Buchannan R, Diehl D, Niu HS, Rupprecht CE (1998) Efficacy of an oral vaccinia-rabies glycoprotein recombinant vaccine in controlling epidemic raccoon rabies in New Jersey. J Wildl Dis 34:752-763

Scatterday JE, Schneider NJ, Jennings WL, Lewis AL (1960) Sporadic animal rabies in Florida. Public Health Rep 75:945-954

Schmitz DA, Brown TC (1994) An assessment of invasive nonindigenous species in Florida's public lands. Florida Dept. Environmental Protection, Tallahassee $283 \mathrm{pp}$

Seward N, VerCauteren K, Witmer G, Engeman RM (2004) Feral swine impacts on agriculture and the environment. Sheep Goat Res J 19:34-40

Sidwa TJ, Wilson PJ, Moore GM, Oertli EO, Hicks BN, Rohde RE, Johnston DH (2005) Evaluation of oral rabies vaccination programs for control of rabies epizootics in coyotes and gray foxes: 19952003. J Am Vet Med Assoc 227:785-792

Slate D, Rupprecht CE, Rooney JA, Donovan D, Lein DH, Chipman RB (2005) Status of oral rabies vaccination in wild carnivores in the United States. Virus Res 111:68-76

Slate D, Rupprecht CE, Donovan C, Badcock J, Messier A, Chipman RB, Mendoza M, Nelson KM (2008) Attaining raccoon rabies management goals: history and challenges. In: Dodet B, Fooks AR, Müller T, 
Tordo N (eds) The scientific and technical department of the OIE. Towards The Elimination of Rabies in Eurasia, Karger, Basel 131: 439-447

Slate D, Algeo TP, Nelson KM, Chipman RB, Donovan D, Blanton J, Niezgoda M, Rupprecht CE (2009) Oral rabies vaccination in North America: opportunities, complexities, and challenges. PLoS Negl Trop Dis 3(12):e549. https://doi.org/10.1371/journal.pntd.0000549

Slate D, Saidy B, Nelson KM, Algeo TP, Kirby J, Vercauteren K, Chipman RB (2015) Raccoon population density indexeS in the eastern United States. Abstracts, The Wildlife Society Annual Conference. Winnipeg, Manitoba

Smith HT, Engeman RM (2002) An extraordinary raccoon density at an urban park. Can Field Nat 116:636-639

Smyser TJ, Beasley JC, Olson ZH, Rhodes OE Jr (2010) Use of rhodamine $\mathrm{B}$ to reveal patterns of interspecific competition and bait acceptance in raccoons. J Wildl Manag 74:1405-1416

Smyser TJ, Redding JV Jr, Bevis CM, Page K, Swihart RK (2015) Development of an automated dispenser for the delivery of medic- inal or vaccine-laden baits to raccoons (Procyon lotor). J Wildl Dis 51:513-518

Steelman HG, Henke SE, Moore GM (1998) Gray fox response to baits and attractants for oral rabies vaccination. J Wildl Dis 34:764-770

Steelman HG, Henke SE, Moore GM (2000) Bait delivery for oral rabies vaccine to gray foxes. J Wildl Dis 36:744-751

Thulke H-H, Eisinger D (2008) The strength of 70\%: revision of a standard threshold of rabies control. Dev Biol 131:291-298

USDA (United States Department of Agriculture) (2005) Cooperative rabies management program national report 2005. USDA/APHIS/ Wildlife Services, Concord, NH

Wandeler AI, Salsberg EB (1999) Raccoon rabies in eastern Ontario. Can Vet J 40:731

Wooding JB, Hardisky TS (1990) Coyote distribution in Florida. Fla Field Nat 18:12-14

World Health Organization (WHO) (1987) Guidelines for dog rabies control. VPH/83.43 rev. 1. World Health Organization, Geneva 